\title{
THE PERFORMANCE AUDIT OF A CORPORATE WEBSITE AS A TOOL FOR ITS INTERNET MARKETING STRATEGY
}

\author{
Iryna Golyash \\ Department of Audit, Revision and Analysis \\ Ternopil National Economic University \\ 3 Peremohy sq., Ternopil, Ukraine, 46020 \\ iryna.golyash@gmail.com \\ Valentina Panasiuk \\ Department of Accounting in the Production Industry \\ Ternopil National Economic University \\ 3 Peremohy sq., Ternopil, Ukraine, 46020 \\ tina.panasjuk@gmail.com \\ Svitlana Sachenko \\ Department of Audit, Revision and Analysis \\ Ternopil National Economic University \\ 3 Peremohy sq., Ternopil, Ukraine, 46020 \\ s_sachenko@yahoo.com
}

\begin{abstract}
The paper discusses the issues of ensuring a performance of the corporate website that, therefore, facilitates the fulfillment of the strategic development goals of the enterprise. The efficiency of the audit for improving the online business management mechanisms is justified. The organizational and methodological peculiarities of the performance audit of the corporate website are reviewed. The usefulness of quantitative indicators received via analytical online-services is determined, and their applicability in the performance audit of the corporate website is confirmed. A special attention is drawn to the possibility of transforming quantitative indicators into the data necessary for the decision-making. The article suggests the use of the key performance indicators of the corporate website calculated on the basis of the numerical value of the quantitative indicators. Based on the clustering method, the ratio between the key indicators of the corporate website performance and the development goals of the enterprise is defined thereby making the objectives of the enterprise tangible and understandable for its management staff. It is claimed that the audit results encourage achieving the desired enterprise performance rates as well as fulfilling its strategic development goals.
\end{abstract}

Keywords: audit, corporate website, strategic goals, efficiency, key indicators.

\section{Introduction}

The ultimate purpose of any enterprise is to make profits. There are many ways to achieve this aim. However, nowadays the only companies that become successful are the ones doing their best to speed up the product sales by lessening the number of intermediaries in the chain "producer - distributor - dealer - retailer - buyer". Such an approach requires the enterprises to meet the demands of the market and adapt their business to the use of the Internet marketing technologies. The introduction of such technologies enables the companies to automate the customer service procedure, effectively organize the feedback, and quickly receive marketing data.

Experience has proven that most enterprises tend to focus on the customer loyalty and communication with them by means of the websites. Nevertheless, the effective business management requires the enterprises to promote their own websites, monitor customers' needs and optimize the online marketing strategy.

The fulfillment of the objectives set is possible with the help of the audit aimed at improvement of the business management mechanisms by means of Internet. 


\section{Analysis of the literature data and statement of the problem}

The numerous scientific papers investigate the issues of Internet marketing and its main tools. In particular, some authors [1] consider the website as the main tool for the content publishing which may become very effective in the long run.

Some of researchers [2] study the response to the information posted on the corporate website, and emphasize the necessity to check the information available online.

Some authors [3] note the significance of the Internet in the field of marketing research and pay attention to its sufficient influence on the business. At the same time, the scholars describe corporate website not only as an information source for the business management but also as a powerful tool for the research.

Separate research works [4] considers the website as the principal instrument for the business development and points out that the information on the product proposal reaches the customer only due to its correct advertising and promotion via website.

Some experts [5] examine the business management mechanism by means of Internet and researches trends in the development of the modern websites.

The research papers largely address the strategic priorities of Internet marketing and characterize its instruments, though the issue of their efficiency has not been properly studied. This is due to the difficulties in choosing the basic assessment criteria, the system of indicators, sources for improving the efficiency, and use of the appropriate research methodology. Therefore, this article attempts to illustrate the challenges of (1) achieving the efficiency of the main Internet marketing tool - corporate website - and thereby (2) ensuring the fulfillment of the strategic development goals.

It should be pointed out that the strategies for achieving the corporate website efficiency should be science-based, i. e. involving the contemporary methods of receipt and processing of information suitable for the strategic management of the enterprise. To that end, the use of audit as a tool for the enhancement of the company performance now becomes very widespread.

The review of the existing publications shows that the research of the audit specifically used for the determination and further ensuring the corporate website efficiency is virtually neglected. The scholarly papers predominantly focus on the traditional audit aimed at the research of the financial and economic activities of the enterprise. Yet the modern tendencies transform the management processes and redirect the audit towards the consultancy services [6], creating the basis for the audit of the corporate website.

Currently, the audit is constantly evolving so that the system of theoretical knowledge is also being improved and adapted to the practical purposes. The modern practice is directly related to the development of information and communication technologies. This fact influenced the development of audit and oriented its functions towards the Internet marketing. The fact that the audit is now used in the field of Internet marketing justifies the necessity to elaborate and use the synergic approach for the research of the audit purposes. It marks the beginning of the new stage in the development of audit when the theory is formed in accordance with the needs of the market economy [7].

In this regard, there are many controversial issues, which are to become the object of the serious and deep scholarly analysis. It is believed that these questions deserve the particular attention.

Importantly, unlike the theoretical investigation, the auditing practice of the corporate website is considered to be more advanced.

Currently there is a range of the new online analysis tools facilitating the automation of the data search necessary for the website audit, which are based on the comprehensive approach. These services give the opportunity to get information on how the corporate website is functioning at the moment. However, the functionality of such services is restricted, as far as they cannot critically assess the user behaviour, establish a link between the analytical data and the desired performance rates of the enterprise, and, finally, anticipate the fluctuation of the indicators under investigation. The automation of these functions is currently impossible, that is why it is believed that such activity requires experts who have relevant knowledge and skills to improve the website audit by means of the comprehensive assessment of its efficiency. 
The audit of the corporate website should not only improve site's popularity but also enhance its competitiveness and facilitate the income growth. Hence, it may be stated that the current practice of the corporate website audit is not well-adapted to the needs of the enterprises striving to fulfill their strategic development goals.

Presently, the practice of website audit requires systematization of the current experience, which then will be directed to the efficiency research. It is considered that this issue demands more detailed elaboration and sufficient improvement.

\section{Purpose and research tasks}

Having analyzed the contemporary theoretical research and practical application of the Internet marketing, we realized the necessity to justify the specificities of website performance audit and then determine the ways of achieving the desired enterprise performance rates and strategic development goals - points that form the purpose of our research.

In order to achieve this aim we have identified the following objectives:

- to review the issues of providing the efficiency of the corporate website and justify the necessity to use auditing for the improvement of the business management via Internet;

- to evaluate the appropriateness of the data sources via analytical Internet-services in order to carry out the performance audit of the corporate website;

- to prove the necessity to transform the quantitative indicators into the data necessary for the decision-making and improve the methodology of the calculation of the key performance indicators of the corporate website;

- to use the results of the corporate website performance audit for achieving the desired enterprise performance rates and strategic development goals.

\section{Materials and methods of research}

The following scientific methods were used during the process of research:

- method of induction to collect, process and systematize research information;

- method of deduction to process of understanding the problems of ensuring the effectiveness of the enterprise's website;

- methods of synthesis and analysis for justifying the audit characteristics of the company's website;

- method of systematization to choose key performance indicators of the company's website;

- methods of detailing, grouping and generalization in relationship between goals of enterprise development and key performance indicators of the website.

\section{Results}

\section{1. Conditions for the corporate website audit}

So far, the development of information and communication technologies is very dynamic, and their potential opportunities for the society and economy only begin to be extensively used. Only a few years ago the World Wide Web was regarded mostly as a huge library designed to help in searching and accessing to the necessary information [8]. In today's world the number of Internet users is rapidly increasing: now there are more than 3,8 billions of people - 9,6 times as many as in 2000 [9]. More and more enterprises opt for the Internet as an alternative way to promote their products. The growing number of websites demonstrates this tendency. There are over 1,2 billion websites on the World Wide Web today [10].

Generally, the website is a rather broad notion with no explicit and accurate definition. Wikipedia defines the term 'website' as a collection of related web pages, including multimedia content, typically identified with a common domain name, and published on at least one web server [11].

The website is deemed to be the main tool of Internet marketing. The website development, its hosting, and careful management open up the unlimited possibilities to become a market leader and successfully distribute the products [12].

The primary objective of the website audit is to provide the full use of site's marketing potential. The website is believed to reflect the success of the company [13]. 
The main functions of the website include content management as well as the control of the online modules designed to facilitate the interaction and information exchange between the website users, monitoring site statistics, managing the advertising and, additionally, the timely review of the available orders. There may be various activity areas of the newly created website, though the top priority is to attract as many visitors as possible (potential customers).

The audit of the corporate website is recommended in case of its inefficiency in order to clarify the reasons for failure. In this case, the examination focuses on the aspects, such as usability, analysis of the site audience, the strategy of its promotion and assessment of the site's competitiveness. The website performance audit encompasses the analysis of the content published on the website, testing of the existing website services, the feasibility of the current strategy of the website promotion etc [14].

Practical implementation of the website audit should (1) include the analysis of macro- and microenvironment of the company, the check of the factors, risks, and possibilities for the enterprise's development, (2) facilitate the comprehensive analysis of the market, assessment of the enterprise's market power, determination of the most important paths of the company's development and enhancement of its effectiveness.

\section{2. The peculiarities of the procedure of the performance audit of the corporate website}

The performance audit of the company's website may be organized in one of the following ways:

- self-audit conducted by the Marketing Division staff;

- an audit conducted by the specialized Audit Division within the enterprise itself;

- an audit conducted by the specially organized group within the enterprise including the representatives of different divisions which interact only during auditing;

- an audit conducted by another audit or consultancy firm, e. g. through co-sourcing or outsourcing.

We consider the method of self-audit as the most convenient one for the small enterprises, establishing the specialized division or group - for the middle-sized companies, involving of another audit experts - for the large ones.

Notably, the cost of different types of the performance audit is small as compared with its possible effect, as far as the evaluation of the corporate website is a perfect opportunity to make up an appropriate development of the effective marketing strategy for the enterprise operating on the World Wide Web.

\section{3. Methodological basis of the performance audit of the corporate website}

Auditing and assessment of corporate website performance may be conducted with the help of the source data provided by various web services: Google Analytics, Woopra, Chart beat, Mix panel, Going Up, Go Squared etc. Google Analytics is considered to be the most suitable tool for obtaining the necessary data whereas it is free of charge and available for most users. Meanwhile, the use of the only one analytical tool for obtaining the source data necessary for the audit is deemed ineffective, because automatically processed information may be corrupted, so that the decisions made on such basis may be wrong. Hence, for obtaining more accurate data it is recommended to compare the indicators provided by different sources. At this point, web analytics would create the opportunities for the full-fledged information-gathering, subsequent auditing and reliable assessment of its results.

The audit procedures make use of the system of indicators. including the following types: verbal (descriptive) indicators, quantitative indicators, qualitative indicators, universal indicators, specific indicators [15].

If the whole system of indicators is involved in the process of auditing, it may result in the excessive waste of time and the greater possibility to analyse the unnecessary data. In this regard, there is a need to single out the indicators appropriate for the audit most of all.

We may suppose that these could be absolute quantitative indicators that could be obtained via various online services. Here is the list of the quantitative indicators appropriate for the per- 
formance audit of the corporate website (Table 1). The selection criteria include easy monitoring, absence of contradictions and usability.

Table 1

Absolute quantitative indicators for the performance audit of the corporate website

\begin{tabular}{ll}
\hline Absolute quantitative indicators & Characteristics \\
\hline
\end{tabular}

Total number of the website accesses

Number of the website accesses over a given period

Number of the website accesses (according to the source of the access)

Characterize the size of the website audience

Number of accesses to the certain page

Number of purchases via website

Number of customers made at least one purchase

Number of accesses ended up on the landing page or the first page

Characterize user activity

The average duration of the visit

Amount of orders in quantitative and monetary terms

Characterize the current marketing activity of

Volume of sales in quantitative and monetary terms the company

Source: Summarized by the authors in accordance with the given data Google Analytics [16]

The particular advantage of the audit is the possibility to transform the quantitative characteristics into the data necessary for the decision-making. In so doing, it is important to identify the indicators corresponding to the needs of the enterprise. Unlike absolute quantitative indicators, these ones should be relative. They are to be related to the time characteristics and show the ratio between the compared and absolute measures. Such practice will provide the opportunity to identify their variability [17]. The change of the relative quantitative indicator must justify the change of the performance indicator. Therefore, the audit must be particularly focused on the research of the key indicators necessary for achieving the efficiency of the corporate website. The key indicators must be calculated by the identification of the ratio and based on the use of the numerical value of the quantitative indicators obtained via analytical web-services.

Table 2 represents the list of the key website performance indicators. Taking into account specificity of the each website, the number of key indicators for the identification of its efficiency may be defined on the individual basis. That is why it is important to develop the separate methodological framework for the performance audit that considers the specificity of the e-environment of each specific company and enables to concentrate on the narrow aspects of the use of its web resources.

When choosing the system of key indicators it is offered to use the constrained optimization strategy implying that the achievement of a certain aim is constrained by the necessity to achieve other aims at an acceptable level. In this case, the ability to keep the balance between the company's goals stands as the criteria for efficiency. In our view, the data on 12-15 key indicators is enough to control the degree of corporate website efficiency as well as to monitor its activities in the field of Internet marketing as the whole. 
Table 2

Key performance indicators of the corporate website

\begin{tabular}{|c|c|}
\hline Indicators & Identification procedure \\
\hline $\begin{array}{l}\text { Effectiveness of the source } \\
\text { of the website traffic }\end{array}$ & $\begin{array}{l}\text { The ratio of the number of accesses (in accordance } \\
\text { with the source of the website access) to the total } \\
\text { number of accesses }\end{array}$ \\
\hline $\begin{array}{l}\text { Frequency of the website } \\
\text { accesses }\end{array}$ & $\begin{array}{l}\text { The ratio of the total number of accesses to the peri- } \\
\text { od of auditing }\end{array}$ \\
\hline $\begin{array}{l}\text { Attendance rate of every } \\
\text { page of the website }\end{array}$ & $\begin{array}{l}\text { The ratio of the number of page views to the total } \\
\text { number of accesses }\end{array}$ \\
\hline Average page-viewing time & $\begin{array}{l}\text { The ratio of the website viewing time to the total } \\
\text { number of accesses. }\end{array}$ \\
\hline Users' involvement rates & $\begin{array}{l}\text { The ratio of the total number of website accesses } \\
\text { over the current and previous time period }\end{array}$ \\
\hline Bounce rate & $\begin{array}{l}\text { The ratio of the users who left website's landing } \\
\text { page or viewed only one page to the total number of } \\
\text { website accesses }\end{array}$ \\
\hline Scroll reach & $\begin{array}{l}\text { The ratio of the total number of the website } \\
\text { accesses to the number of website accesses over } \\
\text { the certain period }\end{array}$ \\
\hline
\end{tabular}

number of website accesses

The ratio of the number of purchases via website to

The propensity of the e-commerce in the company

The share of the online customers becoming the regular ones.

The average cost of one purchase

Costs of one website visit

Costs of the involvement of one online customer

Growth (decline) of income from the e-commerce the total sales of the company

The ratio of the total number of purchases via website to the number of clients made at least one purchase

The ratio of the product sales via website in the monetary terms to the number of customers

Reflects the effectiveness of the sources of the website access

Demonstrates how frequently users visit the website

Characterizes the popularity of the certain website page

Characterizes the users' interest

Enables to assess the attendance rate compared to the previous time period

Characterizes the attractiveness of the website for the users

Characterizes the user behaviour

Enables to analyse the evolution of the buyers' preferences against the total number of the website accesses.

Reflects the changes concerning the share of the e-commerce in the company's activity

Enables to track the share of the new clients

Shows the average purchase price

The ratio of the total costs of the website development and maintenance to the frequency of the website accesses

Enables to analyse the company's expenses

The ratio of the total costs of the website development and maintenance to the number of customers made at least one purchase

Enables to analyse the current expenses

Reflects the changes in the product revenue

The ratio of online sales in monetary terms over the current or previous time period

The ratio of the total costs of the website development and maintenance to the number of purchases via website

Enables to analyse cost-effectiveness 


\section{4. Application of the audit results for achieving strategic development goals of the en- terprise}

Key website performance indicators should encourage the implementation of the concrete steps towards the achievement of the desired enterprise performance rates and strategic development goals (Table 3).

Table 3

Interrelation between the company development goals and the key performance indicators of its website

\begin{tabular}{|c|c|c|}
\hline \multicolumn{3}{|c|}{ Enterprise development goals } \\
\hline Strategic goals & $\begin{array}{l}\text { Desired enterprise } \\
\text { performance rates }\end{array}$ & $\begin{array}{l}\text { Key performance indicators of } \\
\text { the corporate website }\end{array}$ \\
\hline \multirow{3}{*}{$\begin{array}{l}\text { Improving the financial per- } \\
\text { formance of the enterprise and } \\
\text { achieving high profits }\end{array}$} & $\begin{array}{l}\text { Increasing the number of } \\
\text { website visitors }\end{array}$ & $\begin{array}{l}\text { Efficiency of the website traffic source } \\
\text { Frequency of website visits } \\
\text { Statistics of attendance of each website page } \\
\text { Average page-viewing time } \\
\text { Users' involvement rates } \\
\text { Bounce rate } \\
\text { Scroll reach }\end{array}$ \\
\hline & Increasing product sales & $\begin{array}{l}\text { Conversion rates } \\
\text { The propensity of the e-commerce in the company } \\
\text { The share of the online customers becoming the regular } \\
\text { ones }\end{array}$ \\
\hline & $\begin{array}{l}\text { Cost reductions, income } \\
\text { growth }\end{array}$ & $\begin{array}{l}\text { The average cost of one purchase } \\
\text { Costs of the one website visit } \\
\text { Costs of the involvement of one online customer } \\
\text { Growth (decline) of income from the e-commerce } \\
\text { Costs of one purchase via website }\end{array}$ \\
\hline
\end{tabular}

Source: grouped by the authors

Identification of the key performance indicators of the website must correlate with their adaptability to the specific goals set by the enterprise. Moreover, the goals of the enterprise should become tangible and understandable for its management staff. The monitoring of key performance indicators and their potential influence on the extent to which the enterprise's goals are being achieved can justify the website efficiency.

The performance audit procedure must be supplemented by a special report. The report should include all the necessary data for the subsequent elaboration of the enterprise development strategy. The report should also contain the list of the concrete steps for enhancing the website efficiency. The recommendations should focus on the improvement of the key performance indicators of the corporate website, which will soon promote the fulfillment of the enterprise development goals.

Thus, it is estimated, that the key indicators must be used for the practical implementation of the performance audit of the corporate website.

The real influence of the website performance audit on the extent to which the goals of the following enterprises have been achieved may be confirmed by the examples presented in Table 4.

According to the Table 4, the audit of several corporate websites proves to encourage the change of key performance indicators and subsequent achievement of the development goals set by the enterprises. The research confirms feasibility of the website audit as the effective tool of Internet marketing strategy. 
Table 4

Practical illustration of the results of the corporate website audit

Enterprise where the website audit was conducted

RTTS Company

“JV BUSINESS CAR" LLC

Stoun Corian Company

CATTON'S Company

Energy Company

Russian Mine and Pumping Company

\section{Changes of the key performance indica-} tors of the corporate website
Results
Conversion rate grew by $50 \%$

- Bounce rate lowered by $15 \%$

- Scroll reach grew twice

- Conversion rate (by the number of orders) grew 1.5 times

- Bounce rate lowered by $27 \%$

- Scroll reach grew twice

- Number of unique visitors grew four-

fold a month

- Conversion rate grew 3.5 times

- Number of unique visitors grew four-

fold a month

- Bounce rate lowered by $17 \%$

- Scroll reach grew twice
1. The desired enterprise development rates are obtained

(the number of website visitors has increased, the value of orders and sales has grown) 2 . The financial performance rates of each company are expected to improve

Source: on the basis of [19]

\section{Discussion of the research results}

The conducted research will enable enterprises to obtain concrete results and formulate recommendations to increase effectiveness of the corporate website based on audit information. This research will enable achievement of company's strategic goals.

The experience of enterprises which uses a practical audit to test the effectiveness of websites shows positive changes in their activities, which include: full information submitting for management staff with reliable information about all marketing activities, ongoing monitoring of key performance indicators of the corporate website, achievement of necessary development results (website visitors growth, value of orders and sales growth), improving the financial performance rates of each company. It confirms the real influence of the website effectiveness audit's results to the level of desired enterprise performance rates and strategic development goals achievement.

\section{Conclusions}

The necessity to improve the theoretical as well as the organization and methodological tools used for ensuring the corporate website performance through audit and eliminating the identified discrepancies lead to the following conclusions: 
1. As the rule, the scholarly papers present solely traditional view of audit aimed at the research of the financial and economic activities of the enterprise. Yet the modern tendencies transform the management processes and redirect the audit towards the consultancy services creating the basis for the audit of the corporate website. The primary objective of the website audit is to provide the full use of site's marketing potential. The corporate website audit is usually recommended in case of its inefficiency for clarifying the reasons for failure.

2. The audit should particularly focus on the investigation of the key performance indicators of the corporate website. It may be stated that these indicators should be related to the time characteristics and show the ratio between compared and absolute measures providing the opportunity to identify their variability.

3. When choosing the system of key indicators it is offered to choose the constrained optimization strategy implying that the achievement of a certain aim is constrained by the necessity to achieve other aims at an acceptable level. Thus, the efficiency criterion equals the ability to keep the balance between the company's goals in various fields of activity. The authors claim that the data on 12-15 key indicators is enough to monitor the degree of company website efficiency.

4. The possibility to transform the quantitative indicators into the data necessary for the decision-making is viewed as a substantial advantage of the audit. Hence, the key performance indicators of the corporate website should encourage the concrete actions for the achievement of the desired enterprise performance rates as well as the fulfillment of the strategic development goals.

The subsequent researches are eventually to focus on the in-depth study of the performance audit methodology, elaboration of the concrete recommendations concerning the performance audit on the Internet and advancing the software for automation of the corporate website audit.

The authors hope that the proposals elaborated in this paper would be useful for both scholars studying the Internet marketing tools and practitioners striving for the efficiency of the corporate website performance.

\section{References}

[1] Cox, J., Dale, B. G. (2002). Key quality factors in Web site design and use: an examination. International Journal of Quality \& Reliability Management, 19 (7), 862-888. doi: 10.1108/02656710210434784

[2] Flanagin, A. J., Metzger, M. J. (2007). The role of site features, user attributes, and information verification behaviors on the perceived credibility of web-based information. New Media \& Society, 9 (2), 319-342. doi: 10.1177/1461444807075015

[3] Kursan, I., Mihic, M. (2010). Business intelligence: The role of the internet in marketing research and business decision-making. Management: Journal of Contemporary Management Issues, 15 (1), 69-86.

[4] Gide, E., Riad Shams, S. M. (2011). The role of web-based promotion on the development of a relationship marketing model to enable sustainable growth. Procedia Computer Science, 3, 1060-1073. doi: 10.1016/j.procs.2010.12.174

[5] Pastore, S. (2012). The Role of Open Web Standards for Website Development Adhering to the One Web Vision. International Journal of Engineering and Technology, 2 (11), 1824-1834.

[6] Golyash, I., Galushka, N. (2008). The Concept of Marketing Audit: Problems of Theory and Practice. Journal of European Economy, 3, 290-297.

[7] Golyash, I. (2009). Issues Regarding Implementation of Computer Information Technologies into Auditing Practices. IEEE International Workshop on Intelligent Data Acquisition and Advanced Computing Systems: Technology and Applications, 597-600.

[8] Leiner, B. M., Cerf, V. G., Clark, D. D., Kahn, R. E., Kleinrock, L., Lynch, D. C. et. al. (2009). A brief history of the internet. ACM SIGCOMM Computer Communication Review, 39 (5), 22-31. doi: 10.1145/1629607.1629613 
[9] World Internet Users Statistics and 2017 World. Available at: http://www.internetworldstats. com/stats.htm

[10] The Total Number of Websites. Available at: http://www.internetlivestats.com/total-number-of-websites

[11] Website. Available at: https://en.wikipedia.org/wiki/Website

[12] Chaffey, D., Ellis-Chadwick, F., Mayer, R., Johnston, K. (2009). Internet marketing: strategy, implementation and practice. New Jersey: Prentice Hall, 736.

[13] Shams, S. M. R. (2013). Competitive Advantage in Market Space. E-Marketing in Developed and Developing Countries, 19-38. doi: 10.4018/978-1-4666-3954-6.ch002

[14] Baluk, N. (2011). Marketing Audit Company Website. Bulletin of Lviv Academy of Commerce, $34,123-130$

[15] Chae, B. (2009). Developing key performance indicators for supply chain: an industry perspective. Supply Chain Management: An International Journal, 14 (6), 422-428. doi: 10.1108/13598540910995192

[16] Google Analytics. Available at: https://www.google.com/intl/uk_ALL/analytics/features/analysis-tools.html

[17] Weber, R. (1999). Information Systems Control and Audit. Upper Saddle River: Prentice Hall Inc, 1013

[18] Parmenter, D. (2007). Key Performance Indicators: Developing, Implementing and Using Winning KPI's. Jersey: John Wiley \& Sons, 225.

[19] Matik: Internet Marketing Agency. Available at: http://matik.ru/consulting/work/ 